\title{
MiR-422a promotes loco-regional recurrence by targeting NT5E/CD73 in head and neck squamous cell carcinoma
}

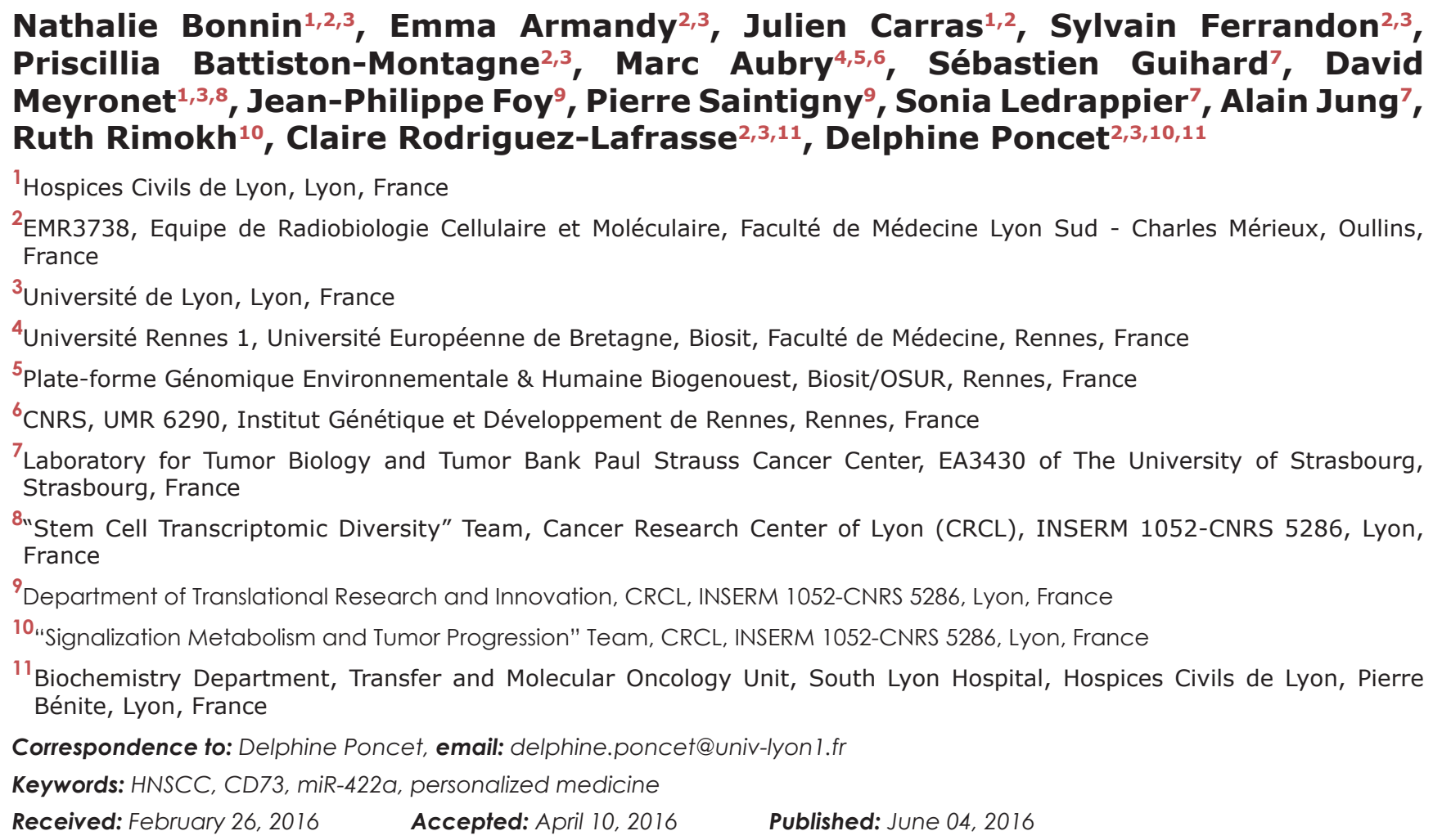

\section{ABSTRACT}

At the time of diagnosis, $60 \%$ of patients with head and neck squamous cell carcinoma (HNSCC) present tumors in an advanced stage (III-IV) of disease and $80 \%$ will relapse within the first two years post-treatment, due to their frequent radio(chemo)resistance. To identify new molecular targets and companion biomarkers, we have investigated the miRNome of 75 stage IIIIV oropharynx tumors without relapse $(R)$ or with loco-regional relapse (nonresponder, NR) within two years post-treatment. Interestingly, miR-422a was significantly downregulated in NR tumors, in agreement with the increase in cell proliferation and adhesion induced by miR-422a inhibition in vitro. Furthermore, we identified CD73/NT5E oncogene as target of miR-422a. Indeed, modulation of the endogenous level of $m i R-422 a$ inversely influences the expression and the enzymatic activity of CD73. Moreover, knocking down CD73 mimics the effects of miR-422a upregulation. Importantly, in tumors, miR-422a and CD73 expression levels are inversely correlated, and both are predictive of relapse free survival - especially considering loco(regional) recurrence - in vitro two independent cohorts of advanced oropharynx or HNSCC $(\mathrm{N}=255)$ tumors. In all, we reported, for the first time, that MiR-422a and its target CD73 are involved in early loco(regional) recurrence of HNSCC tumors and are new targets for personalized medicine. 


\section{INTRODUCTION}

Head and neck squamous cell carcinoma (HNSCC) is the sixth most common cancer worldwide. While tumors in stage I-II are curable, two thirds of patients have tumors in advanced stages (III-IV) at the time of diagnosis, and despite a treatment combining radio(chemo)therapy and surgery (when possible), nearly $80 \%$ will relapse within two years. As a result, the 5-year overall survival (OS) rate is currently under $50 \%$ [1]. More aggressive therapies, such as induction chemotherapy, carbon hadrontherapy, radical surgery or concomitant biotherapy, are available; however, their prescription without the support of predictive biomarkers has failed to improve survival but has increased toxicity [2-4]. Hence, the identification of reliable prognosis/predictive biomarkers has been a matter of intense research in the last decade. The initial strategy to prescribe intensified therapy to patients with a poor-predicted outcome. Meanwhile, dose de-escalation could be envisaged for patients with a good-predicted outcome to reduce the frequency of debilitating side effects (difficulties in swallowing, breathing, eating...), induced by the standard treatment. In this field, the Human Papilloma Virus (HPV) infection - known to be predictive of good outcome - is more and more considered as a marker for dose de-escalation, with encouraging results considering reduced toxicity (NCT01530997). However, treatment intensification based on HPV stratification may not be an adequate treatment strategy, since intensitymodulated radiation therapy (IMRT) improves the survival irrespective of the HPV status [5], and biomarker for dose intensification are awaited. Studies on functional biomarkers have highlighted the importance of biomarkers for hypoxia and positron emission tomography (PET) imaging, for prognosing, but they have so far not been routinely implemented in clinical applications. The difficulty is that HNSCC are heterogeneous tumors with different locations (oral cavity, oropharynx, nasopharynx, larynx and hypopharynx) and different biological histories and risk factors (viral infection, alcohol/tobacco intoxication...) (for review see [6]). Hence, dealing with the tumoral heterogeneity of these cancers is challenging. Recently, extensive genomic and transcriptomic (meta)analyses have characterized four [7] (revised to six [8]) molecular subclasses of HNSCC: Basal, Classical, Mesenchymal and Atypical [7]. This signature has paved the way for the development of personalized treatments, but cannot, as such, be translated into clinical routine tests. To conclude, regarding clinical practices, the challenge is no longer to identify global prognosis/predictive markers to prescribe intensified treatments based on standard chemo-radiotherapy approaches, but instead as Kang et al. proposed, to identify novel therapeutic targets and to develop predictive companion biomarkers [6].

MicroRNA (miRNA) is a good candidate for such a strategy, since it can be easily analyzed in biological fluids and can be directly targeted by innovative therapies. Indeed, 6 clinical trials evaluating an antimiR-122 strategy are on-going in the context of hepatic diseases, and among them one has already entered phase II testing (Santis Pharma Corp.). Furthermore, the identification of microRNA targets could provide us with the opportunity to develop more conventional pharmacological approaches. Regarding the companion tests, these small RNA molecules are efficiently retrieved from (fixed or frozen) tumor samples or from biological fluids, such as blood, urine or saliva, and display high levels of stability over time and tissue specificity [9]. Four miR-based panels dedicated to the diagnosis of lung and kidney cancers are already commercialized for clinical use (Rosetta Genomics). With regards to HNSCC, microRNA signatures with a prognostic or a diagnostic significance have recently been identified, but need to be confirmed by conducting independent studies $[10,11]$. Hence, the heterogeneity in tumor location is a limiting factor in conducting such molecular studies in the case of HNSCC. To circumvent such limitations, the present study proposes a twostep approach, in order to identify target/companion biomarkers for HNSCC treatment strategies. (i) We will initially identify potential target/companion biomarkers in a small yet highly homogenous cohort of patients, who will be selected according to a common criterion, namely the location of the HNSCC, before (ii) applying this personalized strategy to a larger HNSCC cohort encompassing different locations. In this study we have targeted the oropharynx, which is associated with a poor clinical outcome. While the frequency of hypopharynx and larynx tumors is decreasing, due to public policies against alcohol/tobacco consumption, the incidence of oropharynx tumors has gradually risen in the past two decades [12]. Most of the oropharynx tumors in advanced stage are radio(chemo)resistant and recur within the first two years post-treatment, giving rise to secondary cancers, metastases or loco-regional recurrences. Since the initial intra-tumoral context, which gives rise to secondary tumors, metastasis or to loco-regional recurrence is expected to differ, and could be a cause of molecular heterogeneity, we have included only tumors which have relapsed loco-regionally during the first two years post-treatment in our nonresponder (NR) study group, while the responder (R) study group experienced no recurrence within the first two years. Overall, our objectives are (i) to identify a microRNA significantly deregulated in the NR group, (ii) to characterize its putative target(s), and (iii) to evaluate our companion marker/molecular target in a larger HNSCC cohort. 


\section{RESULTS}

\section{$M i R-422 a$ is significantly downregulated in oropharynx tumors from patients who experienced early loco(regional) recurrence}

The level of expression of 384 miRNA was determined by RT-qPCR (TaqMan low density microarray) in 75 stage III-IV oropharynx tumors (36 from NR and 39 from R), and in 38 adjacent healthy tissues (N) (19 from NR and 19 from R). Overall, 13 miRNA were significantly deregulated in NR versus R (Wilcoxon test, $\mathrm{p}<0.05$ ) and were also predictive of relapse-free survival (RFS) (LogRank test, $\mathrm{p}<0.05$ ) (data not shown). We refined our initial analysis and searched for miRNA that could differentiate patients who exclusively experienced local (and not loco-regional) recurrence (Local Rec) from patients who did not recur (R). Among the 13 miRNA initially identified, only the downregulation of $m i R-422 a$ was associated with an exclusively local recurrence (Figure 1A). Furthermore, the level of $m i R-422 a$ expression was also predictive of RFS (LogRank test, $\mathrm{p}<0.05$ ), when considering loco-regional or local relapse (Figure 1B). Regarding the healthy adjacent tissues $(\mathrm{N})$, we observed a significantly higher level of miR-422a compared to tumor samples (Figure 1A, Left part). The RT-qPCR data were confirmed by conducting individual custom-made RT-qPCR experiments (Supplementary Figure S1) and by carrying out in situ hybridization (Figure 1C). Indeed, the intensity of the cytoplasmic and nuclear labelling of the cancer cells (and not of the stromal cells) increased as a function of $m i R-422 a$ expression levels, determined by RT-qPCR (low, medium and high) in the same tumors (Figure 1C). Together with the high cellularity (over 70\%) of our samples, this observation confirms a tumor-specific dysregulation of $m i R-422 a$ expression.

\section{MiR-422a modulates cell adhesion and proliferation but not radio-sensitivity}

To better characterize the function of $m i R-422 a$, we conducted in vitro experiments on three cell lines: SCC61 and SQ20B derived from human HNSCC, as well as $\mathrm{HaCaT}$ derived from normal epithelial cells (all the three expressing $m i R-422 a$ (Supplementary Figure S2)). Cells were transiently transfected with modified oligonucleotides, either mimicking ( $\mathrm{miRmim}$ ) or inhibiting (miRinhi) the endogenous expression of miR-422a. An irrelevant construct was used as a control (miRCo). The efficiency of the transfections was assessed using a fluorescent miRNA, and repeatedly reached $98 \%$ (data not shown). We initially evaluated whether the downregulation of $m i R-422 a$ was responsible for radio-resistance (as local recurrence is indicative of radio-resistance). To do so, we carried out clonogenic assays (standard test for radiosensitivity measurement, Figure $2 \mathrm{~A}$ ) and analyzed cell viability using the CCK8 assay (Figure 2B), after transfection and irradiation, but we repeatedly failed to identify any effect of $m i R-422 a$ modulation on cell sensitivity to X-ray irradiation. Strikingly, one parameter was constantly modified in the clonogenic assays, namely the plating efficiency (PE). The PE corresponds to the proportion of seeded cells able to produce a clone of at least 64 cells, after allowing sufficient time for 6 cellular divisions to occur in control cells. Hence, we observed a significant decrease in the $\mathrm{PE}$ in the miRmim versus the miRCo condition in SCC61 and SQ20B cells, but no modification was noted in $\mathrm{HaCaT}$ cells (Figure 3A). Different hypotheses can account for this decrease in the PE: (i) an increase in basal cell death, (ii) a decrease in the initial cell adhesion, and (iii) a decrease in cell proliferation, as previously reported [13, 14]. We first tested the level of spontaneous apoptosis, but observed no significant effect on the modulation of endogenous $m i R-422 a$ levels in all the three cell lines (Supplementary Figure S3A). In order to determine the strength of adhesion of cells, we measured the maximal impedance signal (at time of full confluence) using the xCELLigence device. We noticed a significant reduction in the adhesive capacity of cells in the miRmim subgroup in SCC61 and SQ20B cell lines only (Figure 3B). Furthermore, the morphology and the actin cytoskeleton of these cells were altered (Figure 3C), since they displayed either a loss of (SCC61) or a disorganized (SQ20B) actin polymerization at the inter-cellular junctions in the miRmim condition. The resulting fibroblastic or round-shaped cells observed in the SCC61 and SQ20B, respectively, is concordant with a reduction in the strength of cell adhesion. Inversely, in the miRinhi condition, we noticed a more intense labelling at the inter-cellular junctions in the SCC61 and SQ20B cell lines. Moreover, no obvious modifications in actin polymerization or cell morphology were visible in the HaCaT cell line. Finally, we tested the consequence of $m i R-422 a$ expression on cell proliferation in our cell lines, and conducted CCK8 assays (Supplementary Figure S3B). We confirmed an increase in cell proliferation in the miRinhi condition and a decrease in the miRmim condition. This effect was clearly visible in SCC61 and SQ20B cells, and less noticeable in the case of $\mathrm{HaCaT}$ cells (but still significant). These findings suggest that $m i R$ $422 a$ induces a combined downregulation of cell adhesion and proliferation, at least in two of the cell lines studied.

\section{MiR-422a targets the oncogene CD73/NT5E}

Among the predicted targets of miR-422a by miR-map (http://mirmap.ezlab.org/app/) and miRecord (http://c1.accurascience.com/miRecords/), we searched for oncogenes known to modulate the adhesion and proliferation processes and tested their level of expression in our tumor samples. Among them, we focused on $C D 73$. This ecto-5'-nucleotidase (also referred as NT5E) is a GPI- 
anchored cell surface protein, which plays enzymatic and non-enzymatic activities. Its oncogenic property partly relies on the modulation of cell adhesion and proliferation [15]. Interestingly, we demonstrated an inverse correlation $(\mathrm{p}<0.01)$ between the levels of expression of miR-422a and CD73 (Figure 4A). Next, we confirmed this inverse correlation by analyzing an independent public dataset (Geoset GS33232), with expression data available for 44 HNSCC tumors and 25 normal tissues (from uvulo-palatopharyngoplasty) (Supplementary Figure S4). Using IHC, we also observed an inverse correlation (Figure 4B) between the level of expression of $m i R-422 a$ determined by RT-qPCR and the intensity of CD73 labelling (the IHC were done on the same four patients as for the ISH). Doing western-blot experiments in basal condition, we barely detected CD73 in the HaCaT cell line (Supplementary Figure S5), we thus focused the subsequent experiments exclusively on the
SCC61 and SQ20B cell lines. Thereby, we observed two bands corresponding to the very recently described isoforms of CD73: the full-length isoform 1 (CD73L, 63kDa) and the short isoform 2 (CD73S, $58 \mathrm{kDa}$ ), deprived of the catalytic domain. Isoform 2 is believed to be specifically deregulated in cancers [16]. As expected, we noticed a clear increase in the total amount of CD73 after the inhibition of endogenous $m i R-422 a$ (miRinhi, Figure 4C) and a decrease (at least in the short isoform) in miRmim in the two cell lines. Next, we measured the enzymatic activity of CD73 in SCC61 cells, and confirmed a clear increase in the case of miRinhi and a decrease in the miRmim condition (Figure 4D). The effect was also visible in the miRinhi condition in SQ20B cells, despite a ten-fold lower basal activity (in relation with a much lower basal protein level). To conclude, miR-422a directly impacts the mRNA and protein level of CD73, as well as its enzymatic activity.
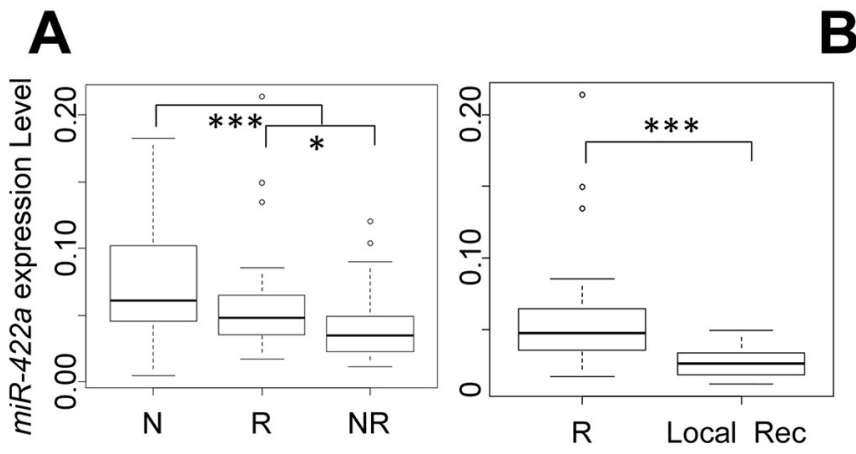

B
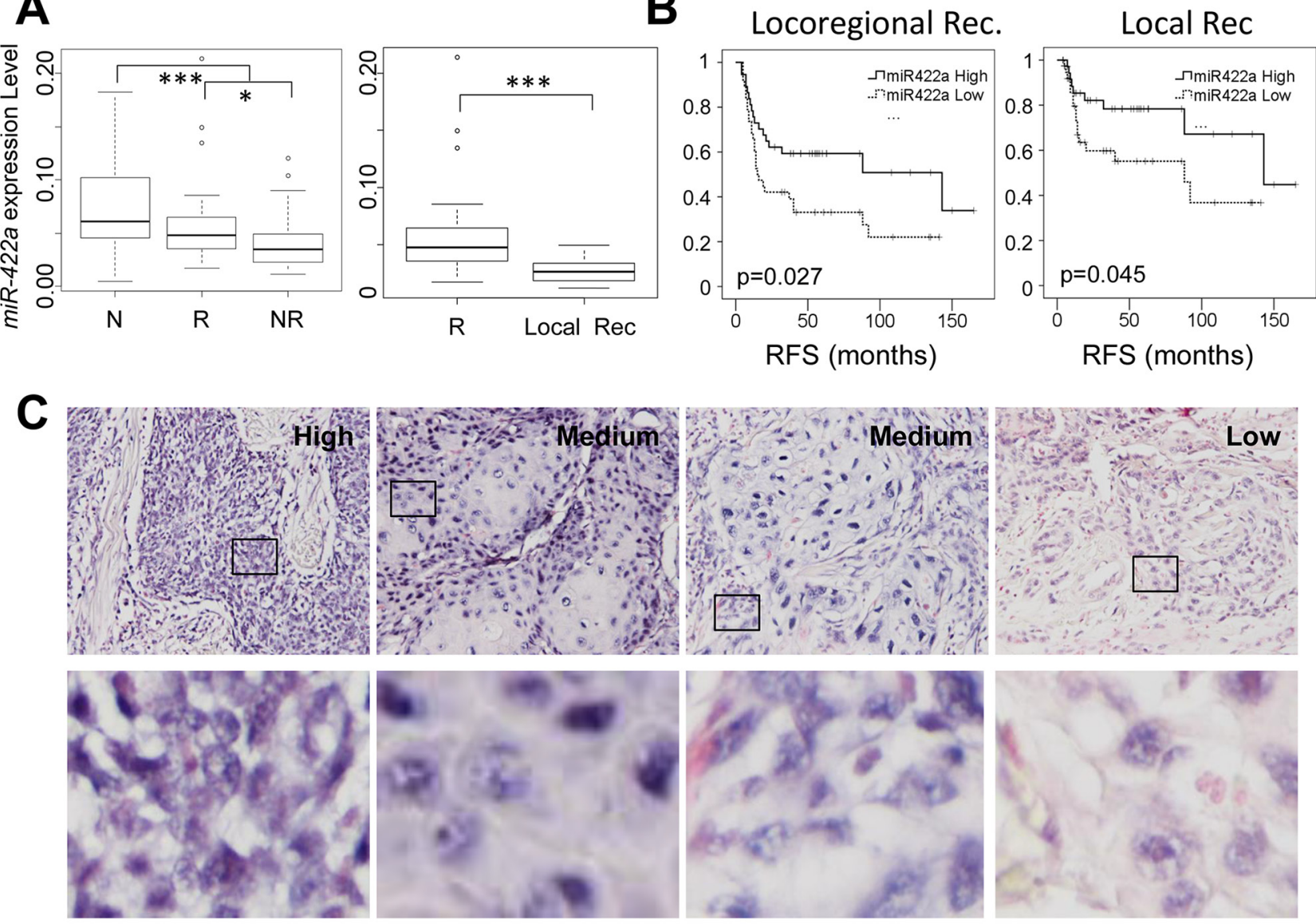

Figure 1: The level of expression of $m i R-422 a$ is downregulated in oropharynx tumors from patients who have experienced early loco-regional recurrence. A. The normalized expression level of $m i R-422 a$ was determined on a TaqMan low density array (TLDA technology). MiR-422a is downregulated in tumor samples (R and NR) compared to healthy adjacent tissues (N), and in the NR versus the R subgroups (on the Left). It is especially downregulated in NR patients exclusively with local recurrence (Local Rec.) (On the Right). Wilcoxon tests were conducted, ${ }^{*} \mathrm{p}<0.05,{ }^{*} \mathrm{p}<0.01,{ }^{* * *} \mathrm{p}<0.001$. B. Kaplan Meier representations of Relapse Free Survival, considering loco-regional recurrence or only local recurrence (Right). C. Representative images (x200 magnification) of miR$422 a$ localization by situ hybridization (purple labelling), on 4 samples with low, high or intermediate levels of $m i R-422 a$ expression, as determined by RT-qPCR. An enhanced image of the outlined area (Bottom) shows an intense cytosolic and nuclear labelling in the high condition, and a faint cytosolic labelling in the "Low" condition, with intermediate levels in the "Medium" condition. 
To confirm the implication of CD73 on cell adhesion and proliferation in our cell lines, we conducted $C D 73$ knocked-down experiments. First, we validated the efficiency of ours siRNAs at the protein and functional levels (Supplementary Figure S5). Next, we inquired the adhesive function of CD73 and as expected, our results confirmed a decrease in the PE in SCC61 and SQ20B cell lines, but not in HaCaT cells, after CD73 knocking down (Figure 5A). Furthermore, a decrease in cell proliferation was clearly noted in all three cell lines treated by siRNA targeting CD73 (Figure 5B). Regarding the cell morphology, CD73 was recently shown to promote cortical actin polymerization and to increase the membranous localization of E-cadherin, $\beta$-catenin, and $\mathrm{Na}+\mathrm{K}+$ ATPase, thereby preserving epithelial integrity [17]. This is in agreement with our observation with regards to an increase in cortical actin polymerization in the miRinhi condition (Figure 3C). To go further, we also noted an increase in membranous E-cadherin labelling in SCC61 and SQ20B cell lines treated by miRinh (Supplementary Figure S6).

To summarize, miR-422a and CD73 have the inverse effects on cortical actin polymerization, and on cell adhesion and proliferation.

\section{Why does CD73/miR-422a modulate cell adhesion and proliferation in a cell-type-specific manner?}

Next, we investigated the differential effect observed on cell adhesion in SCC61 and SQ20B cells versus HaCaT cells. We observed a ten-fold reduction in the level of $C D 73$ mRNA in SQ20B and HaCaT cells (Supplementary Figure $\mathrm{S} 2$ ), which resulted in similar basal enzymatic activities

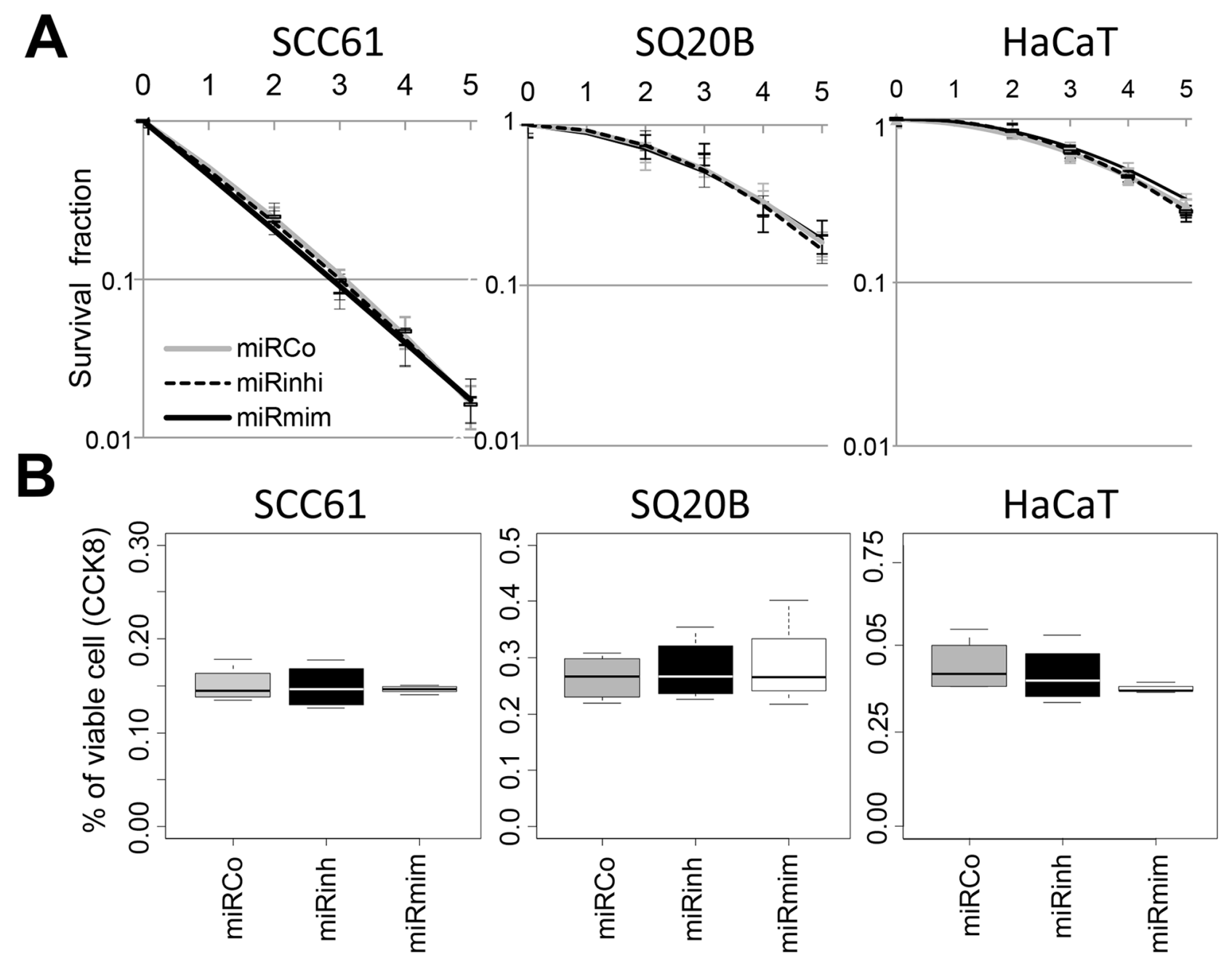

Figure 2: MiR-422a does not modulate cell response to irradiation. A. Clonogenic assays were conducted on three cell lines transfected with either miRCo (control), miRmim (mimic) or miRinhi (inhibitor). The survival fraction is plotted as a function of the dose of X-rays irradiation. B. Cells were irradiated (10Gy) $24 \mathrm{hr}$ post-transfection, and cell viability was determined using the CCK8 assay 5 days after irradiation (percentage of the non-irradiated condition are shown). No significant statistical differences were observed in both experiments. 

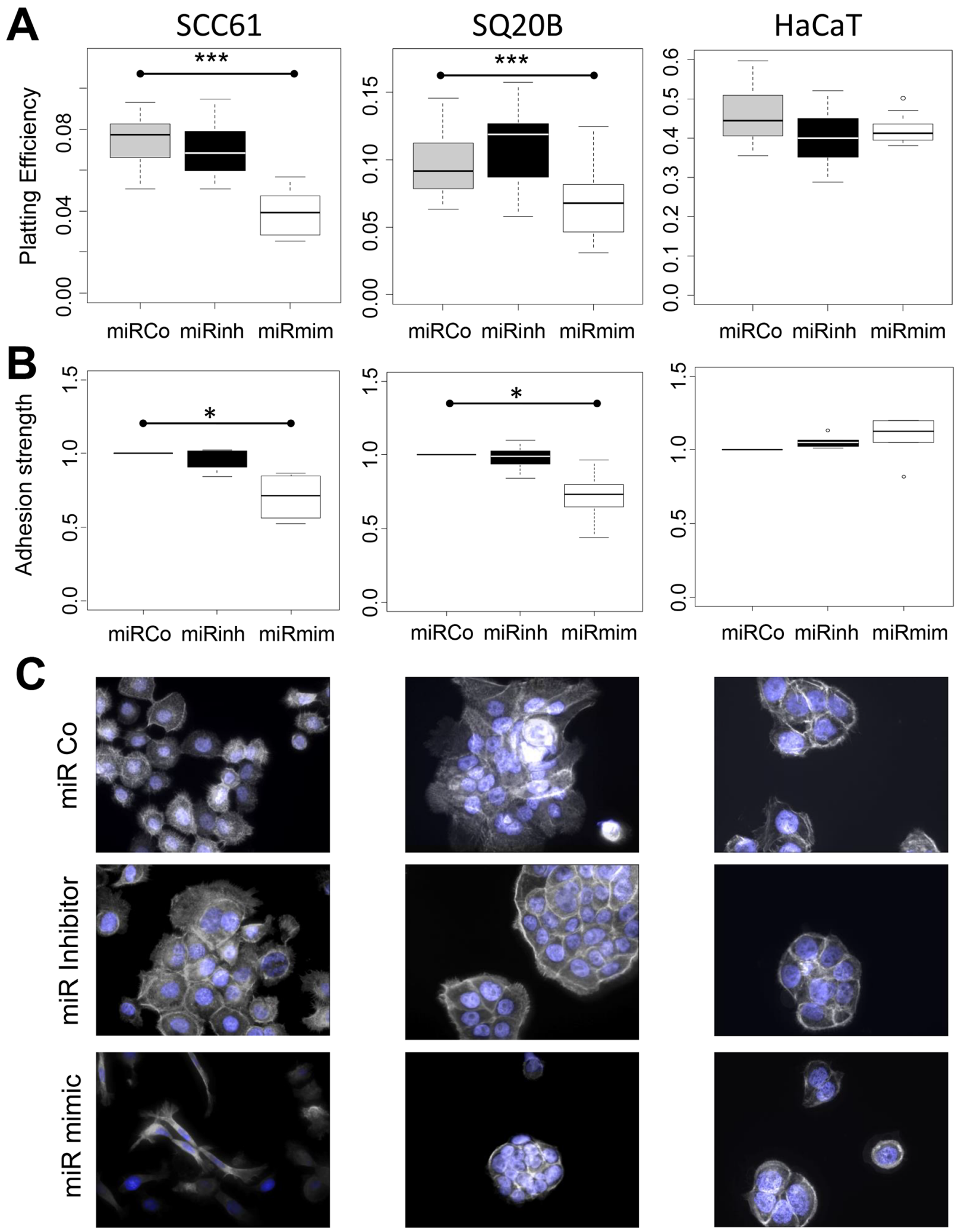

Figure 3: MiR-422a modulates adhesion of SCC61 and SQ20B cells. A. Representation of the plating efficiency. Cells were transfected with the different constructs and plated at a low density. All of the clones were fixed and counted, once the 64-cell stage had been reached in the miRCo condition. For each condition the ratio between the number of clones and the number of plated cells is shown. B. The strength of adhesion (maximal impedance signal) was determined using the xCELLigence assay. Cells were transfected with the different constructs and plated, the signal was determined at full cellular confluence after $48 \mathrm{hr}$ to $72 \mathrm{hr}$. C. Fluorescence imaging of actin cytoskeleton (white) and nucleus (blue) was conducted $48 \mathrm{hr}$ after transfection of the three cell lines (X40 magnification). 
(Supplementary Figure S5). Since the CD73 protein was hardly detected on Western blots of $\mathrm{HaCaT}$ cells, compared to SQ20B cells, this suggests (i) that an additional posttranslational control of CD73 exists in $\mathrm{HaCaT}$ cells, and (ii) that most of the $\mathrm{CD} 73$ protein is dedicated to enzymatic functions in $\mathrm{HaCaT}$ cells. As adhesion is believed to be controlled by the non-enzymatic activity of CD73 [18, 19], we propose that the residual CD73 protein detected in $\mathrm{HaCaT}$ cells may play a minor role in cellular adhesion. However, $\mathrm{HaCaT}$ cells have a much stronger basal adhesion than SCC61 and SQ20B cells (Supplementary Figure S2), thus indicating that this function mainly relies on a different pathway in this cell line. Altogether, these findings explain the absence of measurable effect of $m i R-422 a / C D 73$ modulation on cell adhesion, despite a slight effect on cell proliferation, specifically reported in the $\mathrm{HaCaT}$ cell line.

\section{A high level of $C D 73$ expression is associated with early loco(regional) recurrence in two independent cohorts of patients suffering from HNSCC}

In the ensuing set of experiments, we set the median expression value of $C D 73$ (and $m i R-422 a$ ) as a threshold to separate patients into "high CD73" or "low CD73" subgroups in our oropharynx cohort such as in the TCGA cohort.

Regarding the oropharynx cohort, we confirmed a shorter RFS in the "high CD73" subgroup (All recur., Figure 6A), although this correlation was not significant $(p=0.149)$. Since we demonstrated (above) that CD73 increases the strength of cell adhesion, we speculated that its levels may be lower in tumors with an inclination
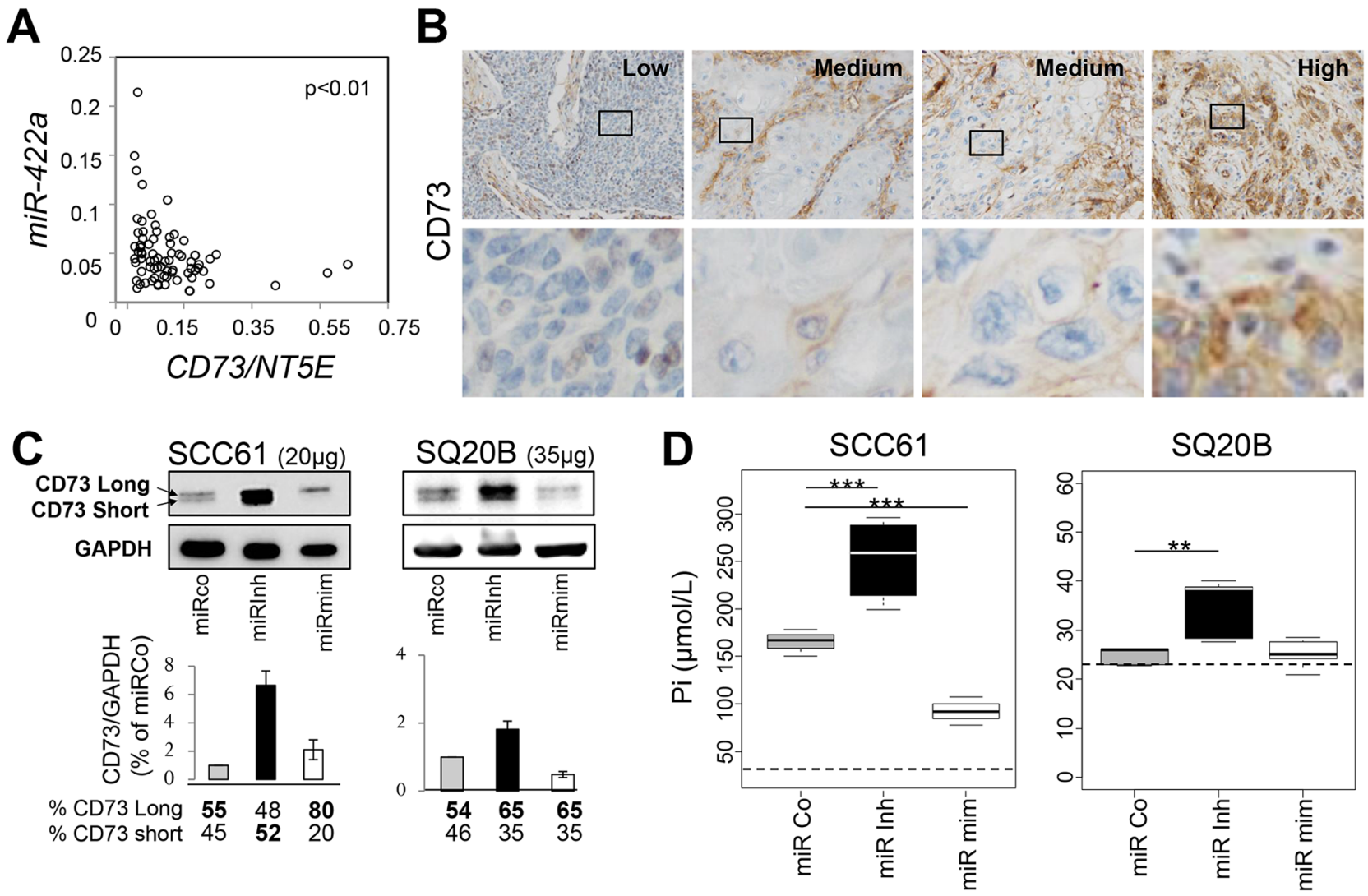

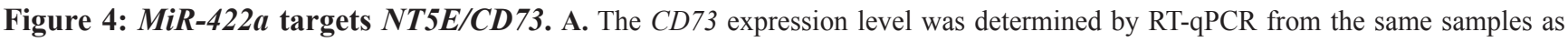
those used for measuring $m i R-422 a$ expression levels, and was significantly inverse correlated with $m i R-422 a$. B. Representative images (x200 magnification) of immunohistochemically labelled CD73 (brown labelling), on the same samples used for ISH, with low, high or intermediate levels of expression of NT5E (and High, medium, and low levels of $m i R-422 a$, respectively, as determined by RT-qPCR). An enhancement of the outlined area is shown below, and reveals an intense membranous labelling in the "High CD73" (but "Low miR-422a") condition, and a faint labelling in the "Low CD73" (but "High miR-422a") condition, with intermediate levels in the "Medium" condition. C. Two days after transfection with the different miRNA constructs, cells were lysed and analyzed for CD73 and GAPDH content by Western blot analysis. The two isoforms (CD73 Long and short) are shown. The signal intensity was determined and normalized (GAPDH) for each isoform of CD73, the total intensity was set at 1 for the miRCo condition. D. Measurement of the enzymatic activity of CD73. Two days after transfection, cells were incubated with $2 \mathrm{mM}$ of AMP for $1 \mathrm{hr}$ and the final concentration of the produced inorganic phosphate (Pi) was measured in the medium. The threshold for detecting Pi was determined and is represented by a dashed line. Wilcoxon tests were conducted, ${ }^{*} \mathrm{p}<0.05, * * \mathrm{p}<0.01, * * * \mathrm{p}<0.001$. 
to produce metastasis. We thus refined our RFS analysis by removing five patients who concomitantly displayed loco-regional recurrence and metastasis (Locoregional, Figure 6A), and observed a significant predictive effect of CD73 expression level on RFS (with an even higher predictive value for $m i R-422 a$ ) (Figure 6A). It is worth noting that due to our initial inclusion criterion (half NR, half R), our cohort is biased towards a higher proportion of responder patients. Since target therapies have been muchawaited for treating patients who are in advanced stage of the disease, irrespective of the initial metastatic status or tumor localization, it was thus necessary to confirm our observations on a non-biased independent cohort of stage III-IV HNSCC tumors.

To do so, we extracted expression data from the TCGA database for 255 patients with stage III-IV tumors of different locations (oral cavity, oropharynx, larynx and pharynx). We observed a significant $(\mathrm{p}=0.018)$ increase in the risk of recurrence in the "high CD73" subgroup (Figure $6 \mathrm{~B}$, All recur.). The significance is maintained when only loco-regional recurrence is included $(p=0.020)$, but is lost when only considering metastasis $(\mathrm{p}=0.154)$, as first event of recurrence. This strengthens the hypothesis that a high expression of $C D 73$ favors loco-regional recurrence, but may be deleterious for the metastatic process. Using the same TCGA database, $m i R-422 a$ expression level was available for 465 samples (of which 42 healthy tissues and 423 HNSCC tissues). However, only $5.8 \%$ of the samples were positive for $m i R-422 a$ expression (maybe due to a lower sensitivity of the technic used), though a lower proportion of positive samples was observed in the tumors $(4.7 \%)$ versus healthy tissues $(16.7 \%)$, what confirmed our result. Selecting the stage III-IV patients $(\mathrm{N}=205)$ and despite a very low number of $m i R-422 a$ positive specimens $(\mathrm{N}=9)$, we drew the RFS curves and observed a clear tendency (obviously not significant) to a longer survival time without recurrence (Figure 6B). Hence, a biotherapy targeting miR-422a/CD73 may be highly beneficial for patients displaying $m i R-422 a \mathrm{Low} /$ $C D 73$ high tumors, to prevent loco-regional recurrence in HNSCC in advanced stages (all locations included).

CD73S, the splice variant of CD73L, is expected to bear the same 3'UTR sequence, comprising the miR$422 a$ binding sites. Since CD73S is presumed to play a major role during oncogenesis [16], we investigated its expression in tumors from the TCGA database and observed a linear correlation between the transcript levels of CD73S and CD73L (in agreement with a co-regulation of both transcripts by $m i R-422 a$ ) (Supplementary Figure S8). Moreover CD73S is predictive of RFS considering
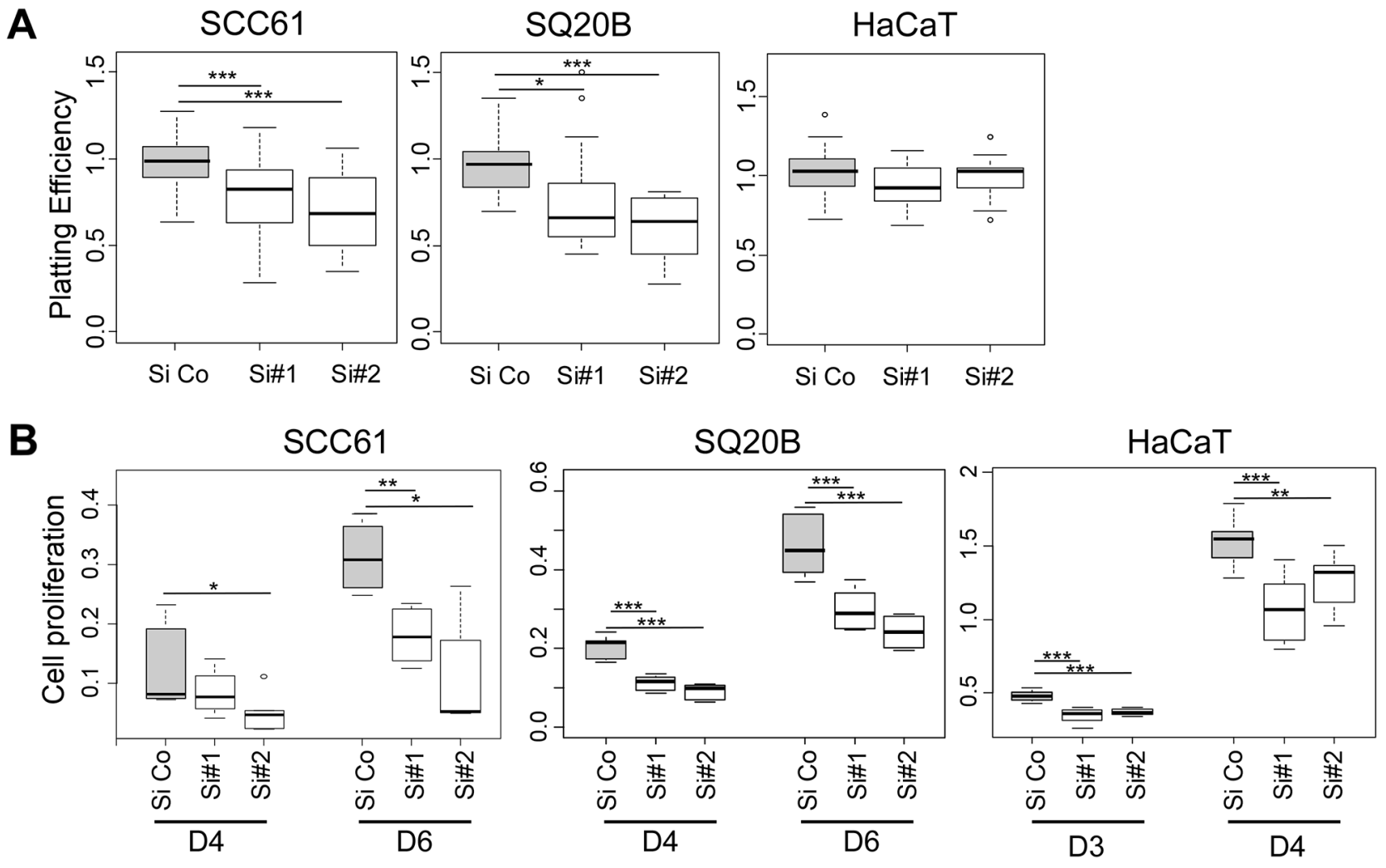

Figure 5: The silencing of $C D 73$ phenocopies $m i R-422 a$ mimic effect. The three cell lines were transfected with an irrelevant siRNA ( $\mathrm{Si} \mathrm{Co}$ ) or with two siRNA targeting CD73 ( $\mathrm{Si} \# 1$ and Si\#2), and plated in different conditions. A. Determination of the plating efficiency. B. Quantification of cell proliferation using the CCK 8 assays at days 4 and 6 post-transfection. The luminescent signal is normalized for 1000 seeded cells. Wilcoxon tests were conducted, ${ }^{*} \mathrm{p}<0.05,{ }^{*} \mathrm{p}<0.01,{ }^{* * *} \mathrm{p}<0.001$. 

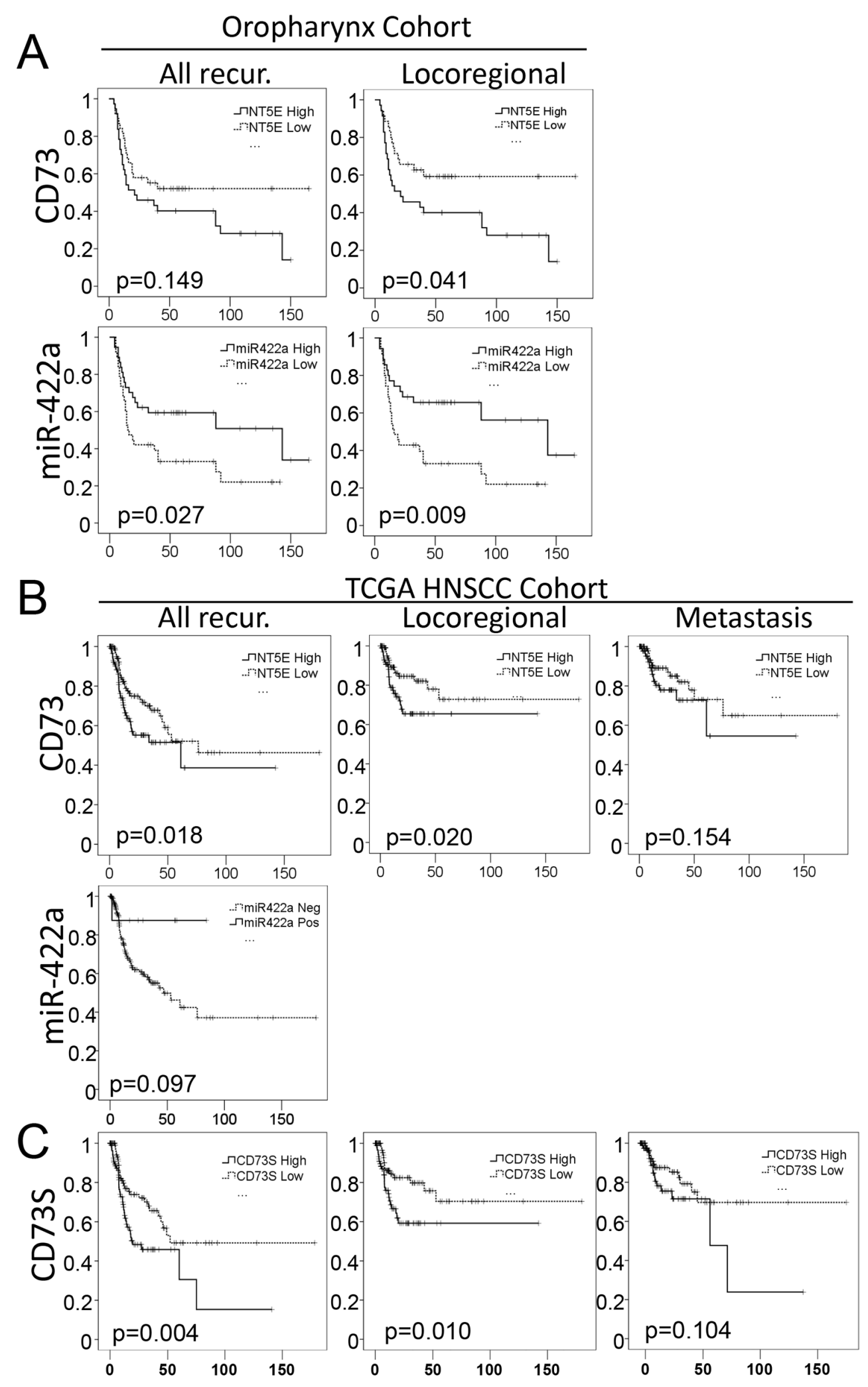

Figure 6: $M i R-422 a$ and $C D 73$ expression levels are predictive of loco(regional) recurrence in two independent cohorts. A. RFS for all of the patients (All Recur) of our oropharynx cohort, or for patients without metastasis at the time of loco-regional recurrence (Locoregional) from the same cohort. B-C. RFS was extracted from the TCGA database, for patients suffering from head and neck tumors (not restricted to oropharynx), at stages III and IV (N=255). Kaplan Meier representation of RFS as a function of total CD73 (B) or CD73S (C) for all types of recurrences (on the Left) or restricted to loco-regional (Middle) or metastatic (Right) recurrences (as first event). LogRank tests were conducted to calculate the p-values. 
all types of recurrences $(\mathrm{p}=0.004)$ or loco-regional recurrences $(\mathrm{p}=0.010)$, but is not predictive of metastasis $(\mathrm{p}=0.104)$ (Figure 6C). To conclude, miR-422a modulates the expression of both CD73S and CD73L, and CD73S bears the same predictive value (with even better $p$-value) with regards to RFS in Head and Neck tumors as compared with total CD73.

Regarding the influence of the clinico-pathological criteria by Cox modeling, we report a significant effect of the resection quality (with a higher risk of recurrence after incomplete resection as expected) in both cohorts (Table 1). We also determined the HPV status in our oropharynx tumors but failed to note any significant effect of this criterion, in both cohorts. This may either be due to a misdetection of the virus or to a low percentage of HPVpositive tumors in the two cohorts (oropharynx cohort $13 \%$ - N=75, TCGA $27 \%$ - N=67). Nevertheless, specific studies addressing the microRNA signature associated with the HPV status in oropharynx did not retrieve $m i R$ $422 a[20]$.

\section{DISCUSSION}

In the present study we have demonstrated that $m i R-422 a$ expression is significantly downregulated in oropharynx tumors from patients who have experienced early loco(regional) recurrence, as well as in tumor compared to normal tissues. MiR-422a downregulation is associated with earlier recurrence in vivo, which may be linked with the stronger cellular adhesion and higher rate of proliferation observed in vitro. We have shown that the mRNA, protein and enzymatic activity of the CD73 nucleotidase, which is involved in the oncogenic processes, are modulated by $m i R-422 a$, and that $C D 73$ downregulation mimics the effects of $m i R$ $422 a$ overexpression. Furthermore, we have proven the predictive value of $m i R-422 a / C D 73$ regarding the loco-regional recurrence of stage III-IV tumors in our oropharynx cohort, as well as in the TCGA cohort encompassing different tumor locations. From these observations, we conclude that $m i R-422 a$ downregulation promotes local recurrence in stage III-IV HNSCC, by targeting CD73.

There is a growing body of evidence strengthening the anti-oncomiR function of miR-422a. Its downregulation in tumoral versus normal tissue has been reported in osteosarcoma [21], in colorectal cancer [13, 22], hepatocarcinoma [14] and gastric tumors [23]. A low expression of $m i R-422 a$ is a marker of poor prognosis in osteosarcoma [21] and colorectal cancer [24] and of poor RFS in hepatocarcinoma [25]. It has also been associated with chemo-resistance in osteosarcoma [26]. Its level of expression in tumors and in serum have been significantly correlated [25], paving the way for its establishment as a companion test. Salivary miRNA profiling has been developed for oral cancer [27]. This non-invasive, rapid and straightforward technique for assessing the expression of miRNA in the vicinity of the tumor, will be the next step in validating the use of miR-422a as a companion biomarker in saliva.

With regards to the function of $m i R-422 a$, its antiproliferative effect has been reported in other cancer cell lines $[13,14]$. Zhang et al. demonstrated its ability to inhibit cell proliferation and migration in vitro, as well as tumor growth and metastasis in vivo, in hepatocarcinoma [14]. They identified FOXG1 as the target of $m i R-422 a$ responsible for these effects in hepatocarcinoma and demonstrated a direct regulation of $m i R-422 a$ expression by FOXG1 (we only observed a faint regulation of $m i R$ $422 a$ expression by our target (Supplementary Figure S7)). FOXG1 was part of our initial screening but its expression was not modified by $m i R-422 a$ modulation in our model (data not shown). Instead, we identified a novel target of $m i R-422 a$, namely CD73. NT5E/CD73 is an oncogene, which is involved in enzymatic and non-enzymatic activities. As an enzyme, its ecto-5'nucleotidase activity is responsible for hydrolyzing ADP into phosphate and adenosine, which in turn initiates adenosine receptor-dependent signals, or is imported into the cell by nucleoside transporters [15]. The adenosine receptor-dependent signaling is used by tumoral cells that overexpress $C D 73$, to facilitate their immune escape $[28,29]$. However, CD73 is also a signaling and an adhesion $[17,18]$ protein involved in metastasis [30, 31], neovascularization[32] and tumor promotion [33], independently of its immune functions. Its overexpression has already been implicated in the resistance to treatment in vitro [34] and in vivo [33].

Regarding the clinical aspects, $C D 73$ overexpression is predictive of a poor prognosis in colorectal, gastric, gallbladder and triple negative breast cancers, as well as in chronic lymphocytic leukemia (for review see [15]). Overall, our results corroborate the pro-adhesive and pro-proliferative functions of CD73, along with its involvement in treatment resistance. However, in our study a high level of $C D 73$ appeared to be unrelated to the metastatic capacity in our cohort and in the TCGA dataset. Consistently, the results published in the literature are conflictual about the pro-migratory and the pro-metastatic function of CD73. In meduloblastoma cell lines, the metastatic potential is inversely correlated with $C D 73$ expression and activity [35]. Pharmacological inhibition of CD73 reduces adhesion but increases the invasion/ migration capacities in vitro [17,36], and treatment with adenosine (produced by CD73) inhibits cell migration and invasion [37]. More recently, loss of CD73 has been involved in epithelial barrier misstructuration and endometrial tumor progression [17].

One plausible explanation of these controversial observations is that numerous factors can influence the consequence of $C D 73$ upregulation, (i) the interaction with the host immune function in vivo, (ii) its participation 
Table 1: Influence of clinical parameter on RFS

\begin{tabular}{lccccc}
\hline & \multicolumn{2}{c}{ Oropharynx stage III-IV } & & \multicolumn{2}{c}{ HNSCC stage III IV (TCGA) } \\
\cline { 2 - 3 } \cline { 6 - 6 } & HR $(\mathbf{C I})$ & $\mathbf{p}$ & & HR (CI) & $\mathbf{p}$ \\
\hline Gender & $0.83(0.37-1.86)$ & 0.646 & & $0.89(0.5-1.58)$ & 0.716 \\
Age & $1(0.97-1.03)$ & 0.901 & & $1(0.63-1.59)$ & 0.998 \\
Stage & $2.38(0.92-6.12)$ & 0.073 & & $1.58(0.91-2.75)$ & 0.106 \\
Margin & $1.59(1.14-2.23)$ & $0.007 * *$ & & $1.54(1.18-2)$ & $0.001^{* *}$ \\
Alcohol/tobacco & $0.8(0.24-2.61)$ & 0.708 & & $1.01(0.64-1.61)$ & 0.963 \\
HPV & $0.43(0.13-1.41)$ & 0.165 & & $0.36(0.05-2.74)$ & 0.327 \\
NT5E & $0.64(0.35-1.18)$ & 0.151 & & $0.6(0.38-0.94)$ & $0.027^{*}$ \\
MiR-422a & $1.99(1.07-3.7)$ & $0.030 *$ & & $3.03(0.42-21.93)$ & 0.271 \\
\hline
\end{tabular}

in enzymatic activities versus its function in adhesion/ signaling, (iii) the destination of adenosine: receptor fixation (while A1, A2A and A2B are pro-proliferative, A3 plays pro-apoptotic functions [38]), or intracellular uptake (which inhibits cell growth and favors apoptosis [39]), (iv) the intra-tumoral cellular subtype expressing CD73 [40, 41], (v) and the isoform that is upregulated. Considering the latter, it was recently shown that the short isoform, CD73S, is responsible for the pro-proliferative activity of CD73 [16] and for the tumor aggressiveness. This is in agreement with the higher significance of the predictive value on RFS of CD73S versus total CD73. CD73S, devoid of its catalytic domain, heterodimerizes with CD73L and inhibits its nucleotidase activity (partly by targeting it to the proteasome). This may explain the increase in the CD73L/CD73S proportion in the miR-mimic condition in SCC61 cells (Figure 5D). Knocking down the short isoform alleviates the proteasomal degradation of $\mathrm{CD} 73 \mathrm{~L}$, which results in the paradoxical increase in CD73L and in an inverse proportion of the two isoforms. With regards to the influence of the cellular sub-population (stromal or cancerous cells) overexpressing CD73 inside the tumor, an increase in the stroma associated with a decrease in the tumoral cells, is associated with a good prognosis in rectal adenocarcinoma [41]. Considering our IHC observations, we also report a differential labelling of the stroma and the tumor for CD73 (Figure 4B), which is in agreement with this publication. Taken together, CD73 is a bi-functional protein, which shares both pro- and anti-oncogenic properties depending on multiple factors.

Targeting the adenosine receptor by anti-A2A drug has reversed the resistance to doxorubicin in mice model of triple negative breast cancer model [33]. However, blocking adenosine receptor only prevents a small part of the oncogenic effect of CD73, and therapeutic antibodies or pharmacological approaches targeting CD73 seem more appropriate to reach a higher therapeutic efficiency. These strategies have demonstrated anti-tumor activity in various xenograft mice models of breast, ovarian, colon and prostate cancers $[30,31,42-44]$ and are now being developed for humans $[45,46]$. Indeed, the anti-CD73 monoclonal antibody MEDI9447 targets and binds to CD73, leading to its clustering and its internalization, abolishing its activity. This immunotherapy combined with anti-PD-L1 is currently under evaluation in phase I clinical trials, for adult solid tumor (NCT02503774). It is thus reasonable to think that HNSCC patients in advanced disease stages with a high intra-tumoral level of CD73 may benefit from MEDI9447 in a near future. However, these drugs should be carefully prescribed taking into account the above mentioned considerations and the immune function of CD73. Furthermore, such an administration should be combined with a treatment preventing metastasis. The targeting of $m i R-422 a$ is also plausible, with innovative therapies targeting microRNA currently being evaluated in clinical trials for different diseases. The drugs available so far can either mimic the microRNA (proMir) or inhibit it (antiMir). For example, the MiRagen Corporation developed a miR$29 \mathrm{~b}$ mimicking strategy to treat fibrosis, and following the successful preclinical assays, the company is now entering phase I of clinical trials. Regarding the antiMir strategy, Miravirsen a drug dedicated to the treatment of hepatitis C, developed by Santaris Pharma, has completed a phase 2 trials. In the near future, targeting $m i R-422 a$ with this kind of molecules could represent a good therapeutic strategy for treating patients with an unfavorable-predicted response to standard radio(chemo)therapy, on the basis of their $m i R-422 a$ value.

\section{MATERIALS AND METHODS}

\section{Clinical specimens}

Fresh frozen samples of oropharynx stage III- IV tumors were obtained from the CRLCC Paul Strauss Center Tumor Bank (Strasbourg, France). Written informed consent was obtained from all patients and the 
study was approved by the local Committee on Human Research. Clinico-pathological and follow-up information were available for all patients (Table 2). Patients had been treated by surgery (the sample are pieces of the surgical resection) and radiotherapy (with or without chemotherapy). Only tissues with high cellularity (over $70 \%$ ) were included. Patients were all negative for metastasis at the time of diagnosis. Patients who did not relapse during the first two years after surgery and radio(chemo)therapy, were considered as responders $(\mathrm{R})$, while patients who experienced local (head and neck localization) and/or regional (nodes involvement) recurrence as a first event, within two years, were considered as non-responders (NR); patients with metastasis as a first event were excluded from the NR group.

\section{Data mining from TCGA and GEOset databases}

We queried The Cancer Genome Atlas (TCGA) data portal and the Global Environmental Outlook (GEO) data portal (http://www.ncbi.nlm.nih.gov/geo). To test for an inverse correlation in the expression levels of $m i R-422 a$ and $C D 73$, we used the GSE33232 series including $44 \mathrm{HNSCC}$ and 25 healthy tissues from uvulopalato-pharyngoplasty. To assess relapse-free survival (RFS), we used the 'TCGA2STAT' R package [47] to download RNAseqV2 normalized read counts (RPKM), as well as miRNASeq normalized read counts (RPMM). Both expression and clinical data were available for 473 HNSCC tumors (from different locations: oral cavity, oropharynx, larynx, and pharynx). RFS for stage IIIIV tumors (with or without metastasis at the time of diagnosis) was available for 255 patients; among them, 179 did not relapse, 40 relapsed loco-regionally, 31 developed metastasis and 4 developed another cancer, as a first relapse event.

\section{Molecular biology}

Total RNA was extracted by using miRNeasy Mini Kit (Qiagen); quality was controlled by the small RNA kit for the Agilent Bioanalyzer (Bio-Rad). $0.7 \mu \mathrm{g}$ of total RNA were reverse transcribed and analyzed using the TaqMan Low density (TLDA) technology (human microRNA panel V2.0) as previously published [48]. The expression data (delta 2 CT method) were normalized against the geometrical mean of three reference genes (Let.7a, miR-26a, Let.7e) chosen according to the GeNorm instructions (https://genorm.cmgg.be/). Custom RT-qPCR were conducted on $m i R-422 a$ and the three reference genes using specific TaqMan ${ }^{\circledR}$ MicroRNA Assays and the same master mix, on a MxPro 3000 (Agilent). In situ hybridization (ISH) against miR$422 a$ was carried out following the instructions of the miRCURY LNA microRNA ISH Optimization kit (Exiqon). Regarding $C D 73$ quantification, $0.5 \mu \mathrm{g}$ of total
RNA were retro-transcribed using the QantiTect RT kit and qPCR were prepared using the QuantiTect SYBR ${ }^{\circledR}$ Green PCR Kit (ThermoFischer Scientific). Primers were designed to amplify the $C D 73$ isoforms 1 and 2 (Fd : TTATTCGACTGGGACATTCG-3', Rs : 5'-AGGC CTGGACTACAGGAACC-3'), the CD73 isoform 2 (Fd: 5'-TGATGAACGCAACAATGGAAT-3', Rs:5'TCTGGAACCCATCTCCACCA-3'), the TATA-box binding protein $(T B P)$ (Fd : 5'-TATAATCCCAAG CGGTTTGC-3', Rs :5'-CACAGCTCCCCACCATATTC $\left.-3^{\prime}\right)$, the ribosomal protein L19 (RPL19) (Fd :5'-GGCACATGGGCATAGGTAAG-3', Rs : 5'-CCATG AGAATCCGCTTGTTT-3') and the glyceraldehyde-3phosphate dehydrogenase (GAPDH) (Fd : 5' GAGTCA ACGGATTTGGTCGT-3', Rs : 5'- TTGATTTTGGAGGG ATCTCG-3'). The level of expression was normalized against the geometrical mean of three reference genes (RPL19, TBP, and GAPDH).

\section{Cell viability and proliferation}

HaCaT, SQ20B and SCC61 cell lines derived from human normal epithelium, larynx and oropharynx tumors, respectively, were cultured as described previously [49]. MirVana microRNA Mimics (ID: MC12541) and Inhibitors (ID: MH12541) specific for $m i R-422 a$, or a Mimic negative control (Ref: 4464058) were transfected under the following conditions for 100000 cells: 6.7 $\mu \mathrm{L}$ of Hiperfect (Qiagen), $0.3 \mathrm{nmol}$ of oligonucleotides in $500 \mu \mathrm{L}$ of final complete medium. Clonogenic assays were conducted as previously described [50]. The surviving fraction was calculated using the formula $\mathrm{S}(\mathrm{D})=\mathrm{n}(\mathrm{D}) / \mathrm{PE} . \mathrm{N}(\mathrm{D})$ where $\mathrm{n}$ is the number of colonies, $\mathrm{N}$ the seeded-cell number for a given dose (D) and PE the plating efficiency $(\mathrm{PE}=\mathrm{n} / \mathrm{N}$, at $0 \mathrm{~Gy})$. Apoptosis was measured $48 \mathrm{hrs}$ post-transfection, using the Annexin- $\mathrm{V}$ and propidium iodide Apoptosis Detection Kit APOAF (Sigma-Aldrich), on an LSRII (Beckman-Coulter) flow cytometer. The number of viable cells was determined by measuring their metabolic activity using the Cell Counting Kit-8 (CCK8) (Sigma-Aldrich). Cells were seeded at different concentrations after transfection in a 96-well plate (4 wells per condition), and cell number was evaluated using the CCK8 on a Luminoskan Ascent Microplate Luminometer (Thermo-Scientific) at day 4 and 6 post-transfection, according to the manufacturer's protocol. Signal (Arbitrary Unit) was normalized for 1000 seeded cells.

\section{Cell adhesion}

To assess the strength of cellular adhesion, cells were seeded after transfection onto a 16-well E-plate (4 wells per condition), and impedance was measured for 3 days on the xCELLigence RTCA DP device (Ozyme). The maximum signal intensity reached at the time of maximum cell confluence, was set as the adhesion 


\begin{tabular}{|c|c|c|c|c|c|c|}
\hline & \multicolumn{2}{|c|}{ NR } & \multicolumn{2}{|c|}{$\mathbf{R}$} & \multicolumn{2}{|c|}{ Total } \\
\hline & No. & $(\%)$ & No. & $(\%)$ & No. & $(\%)$ \\
\hline & 36 & $(48)$ & 39 & $(52)$ & 75 & $(100)$ \\
\hline \multicolumn{7}{|l|}{ Sex } \\
\hline Male & 30 & (83) & 31 & (79) & & \\
\hline Female & 6 & (17) & 8 & (21) & & \\
\hline \multirow[t]{2}{*}{ Age } & Median & (range) & Median & (range) & Median & (range) \\
\hline & 56 & $(39-74)$ & 53 & $(40-82)$ & 54 & $(39-82)$ \\
\hline \multicolumn{7}{|c|}{ Alcohol and tobacco use } \\
\hline Yes & 29 & (81) & 30 & (77) & 59 & (79) \\
\hline No & 3 & (8) & 3 & (8) & 6 & (8) \\
\hline NA & 4 & (11) & 6 & (15) & 10 & (13) \\
\hline \multicolumn{7}{|l|}{ HPV status* } \\
\hline Positive & 3 & (8) & 7 & (18) & 10 & (13) \\
\hline Negative & 33 & $(92)$ & 32 & (82) & 65 & (87) \\
\hline \multicolumn{7}{|l|}{ Disease site } \\
\hline Tonsil & 9 & (25) & 13 & (33) & 22 & $(29)$ \\
\hline Base of tongue & 10 & (28) & 14 & (36) & 24 & $(32)$ \\
\hline Soft palate & 7 & (19) & 4 & (10) & 11 & $(15)$ \\
\hline Pharyngeal wall & 1 & (3) & 3 & (8) & 4 & (5) \\
\hline Vallecula & 5 & (14) & 4 & $(10)$ & 9 & (12) \\
\hline other & 4 & (11) & 1 & (3) & 5 & (7) \\
\hline \multicolumn{7}{|l|}{ Staging } \\
\hline III & 4 & (11) & 9 & $(23)$ & 13 & $(17)$ \\
\hline IV & 32 & (89) & 30 & (77) & 62 & $(83)$ \\
\hline N0 & 3 & (8) & 6 & $(15)$ & 9 & (12) \\
\hline N1 & 4 & (11) & 7 & (18) & 11 & (14) \\
\hline N2 & 22 & (61) & 23 & (59) & 45 & $(57)$ \\
\hline N3 & 7 & (19) & 3 & (8) & 10 & (13) \\
\hline \multicolumn{7}{|l|}{ Treatment } \\
\hline RT alone & 28 & (78) & 30 & (77) & 58 & (77) \\
\hline RT-CT & 8 & (22) & 9 & (23) & 17 & (23) \\
\hline
\end{tabular}

* Sample positive for viral DNA and RNA, RT: radiotherapy, RT-CT: radio(chemo)therapy, NA: not available.

strength. Microscopic imaging was conducted two days post-transfection. Cells were fixed and stained as previously described [49]. The actin cytoskeleton was labelled using phalloidin-FITC (Sigma-Aldrich), and the DNA using Hoechst 33258 (Sigma-Aldrich). Observations were done on an Imager Z2 (Zeiss).
Determination of CD73 activity and protein level

Cells were transfected with Silencer Selected siRNA (Life Technologies): one control and two targeting CD73 (ID: s9735\#2; s9734\#1), under the following conditions for 100000 cells: $6.7 \mu \mathrm{L}$ of hiperfect, $12.5 \mathrm{pmol}$ of 
siRNA in $500 \mu \mathrm{L}$ of final complete medium. Two days after transfection, cells were lysed and protein extracted and analyzed by western-blotting as previously published [49]. Anti-CD73 (ab124525, Abcam) or anti-GAPDH (H86504M, Interchim) were used as primary antibodies and HRP-linked goat anti-rabbit (sc3837, SantaCruz) or goat anti-mouse (sc2031, SantaCruz) as secondary antibodies. Immunohistochemistry (IHC) against CD73 was performed using a Ventana Autostainer Automat (Ventana Medical Systems). Slides prepared from formalin-fixed paraffin-embedded tumor specimens were incubated with an anti-CD73 antibody (ab124525, Abcam; dilution: 1/100). Signals were detected using the ultraView Universal DAB Detection Kit (Ventana Medical Systems), according to the manufacturer's instructions. Nucleotidase activity was determined as previously published [51]. Briefly, after three washes, cells were incubated for 1 to $3 \mathrm{hrs}$ in a medium containing $2 \mathrm{mM}$ ATP. The concentration in inorganic phosphate of the supernatant was then analyzed using the malachite green colorimetric reaction. Standard dilutions of $\mathrm{KH}_{2} \mathrm{PO}_{4}$ solution (10 to $100 \mathrm{mM}$ ) were used to calculate the inorganic phosphate concentration.

\section{Statistical analyses}

Survival analyses were performed with the $\mathrm{R}$ survival package software ( $\mathrm{R}$ software: Language and Environment for Statistical Computing, R Foundation for Statistical Computing, http://www.R-project.org). Cox proportional hazard models provided estimates of the hazard ratios (HRs). For each covariate, we have checked that no evidence of violation of the proportional hazards assumption was found by plotting the scaled Schoenfeld residuals generated by the cox.zph function). A Wilcoxon test was used for mean comparison, while linear correlations were conducted using the spearman test. Considering the relapse free survival analysis: LogRank and Kaplan Meier curve drawings, were done using the SPSS software (IBM, France).

\section{ACKNOWLEDGMENTS}

The experiments were done thanks to the contribution of the SFR BioSciences Gerland-Lyon-Sud (UMS3444/ US8) platforms of flow cytometry and genetic. The microscopy Metasystem platform was financed by LYric INCa-DGOS-4664 and Contrat Plan-Etat-Region ETOILE. We thank Alison Baesa for her participation and Céline Maelys for her help in IHC experiments. We would like to thank B. Manship (CRCL) for her advice on the manuscript.

\section{CONFLICTS OF INTEREST} authors.

\section{GRANT SUPPORT}

D.P. benefits from a INSERM Interface contract and has been supported by La Ligue Contre le Cancer (Comité du Rhône). C.R.L laboratory is part of the scientific framework of Contrat Plan-Etat-Region (ETOILE) and Labex Primes (ANR-11-LABX-0063) of Université de Lyon. C.R.L. was supported by the program "Investissements d'Avenir" (ANR-11-IDEX-0007) operated by the French National Research Agency (ANR).

\section{REFERENCES}

1. Argiris A, Karamouzis MV, Raben D and Ferris RL. Head and neck cancer. Lancet. 2008; 371:1695-1709.

2. Ang KK, Zhang Q, Rosenthal DI, Nguyen-Tan PF, Sherman EJ, Weber RS, Galvin JM, Bonner JA, Harris J, El-Naggar AK, Gillison ML, Jordan RC, Konski AA, Thorstad WL, Trotti A, Beitler JJ, et al. Randomized phase III trial of concurrent accelerated radiation plus cisplatin with or without cetuximab for stage III to IV head and neck carcinoma: RTOG 0522. J Clin Oncol. 2014; 32:2940-2950.

3. Haddad R, O'Neill A, Rabinowits G, Tishler R, Khuri F, Adkins D, Clark J, Sarlis N, Lorch J, Beitler JJ, Limaye S, Riley S and Posner M. Induction chemotherapy followed by concurrent chemoradiotherapy (sequential chemoradiotherapy) versus concurrent chemoradiotherapy alone in locally advanced head and neck cancer (PARADIGM): a randomised phase 3 trial. Lancet Oncol. 2013; 14:257-264.

4. Loo SW, Geropantas K and Roques TW. DeCIDE and PARADIGM: nails in the coffin of induction chemotherapy in head and neck squamous cell carcinoma? Clin Transl Oncol. 2013; 15:248-251.

5. Lassen P, Overgaard J and Eriksen JG. Expression of EGFR and HPV-associated p16 in oropharyngeal carcinoma: correlation and influence on prognosis after radiotherapy in the randomized DAHANCA 5 and 7 trials. Radiother Oncol. 2013; 108:489-494.

6. Kang H, Kiess A and Chung $\mathrm{CH}$. Emerging biomarkers in head and neck cancer in the era of genomics. Nat Rev Clin Oncol. 2015; 12:11-26.

7. Network CGA. Comprehensive genomic characterization of head and neck squamous cell carcinomas. Nature. 2015; 517:576-582.

8. De Cecco L, Nicolau M, Giannoccaro M, Daidone MG, Bossi P, Locati L, Licitra L and Canevari S. Head and neck cancer subtypes with biological and clinical relevance: Meta-analysis of gene-expression data. Oncotarget. 2015; 6:9627-9642. doi: 10.18632/oncotarget.3301.

9. Rosenfeld N, Aharonov R, Meiri E, Rosenwald S, Spector Y, Zepeniuk M, Benjamin H, Shabes N, Tabak S, Levy A, Lebanony D, Goren Y, Silberschein E, Targan N, Ben-Ari A, Gilad S, et al. MicroRNAs accurately identify cancer tissue origin. Nat Biotechnol. 2008; 26:462-469. 
10. Courthod G, Franco P, Palermo L, Pisconti S and Numico G. The role of microRNA in head and neck cancer: current knowledge and perspectives. Molecules. 2014; 19:5704-5716.

11. Jamali Z, Asl Aminabadi N, Attaran R, Pournagiazar F, Ghertasi Oskouei S and Ahmadpour F. MicroRNAs as prognostic molecular signatures in human head and neck squamous cell carcinoma: A systematic review and metaanalysis. Oral Oncol. 2015.

12. Whang SN, Filippova M and Duerksen-Hughes P. Recent Progress in Therapeutic Treatments and Screening Strategies for the Prevention and Treatment of HPVAssociated Head and Neck Cancer. Viruses. 2015; 7:5040-5065.

13. Faltejskova P, Svoboda M, Srutova K, Mlcochova J, Besse A, Nekvindova J, Radova L, Fabian P, Slaba K, Kiss I, Vyzula R and Slaby O. Identification and functional screening of microRNAs highly deregulated in colorectal cancer. J Cell Mol Med. 2012; 16:2655-2666.

14. Zhang J, Yang Y, Yang T, Yuan S, Wang R, Pan Z, Huang G, Gu F, Jiang B, Lin C and Zhou W. Double-negative feedback loop between MicroRNA-422a and forkhead box (FOX)G1/Q1/E1 regulates hepatocellular carcinoma tumor growth and metastasis. Hepatology. 2015; 61:561-573.

15. Gao ZW, Dong K and Zhang HZ. The roles of CD73 in cancer. Biomed Res Int. 2014; 2014:460654.

16. Snider NT, Altshuler PJ, Wan S, Welling TH, Cavalcoli J and Omary MB. Alternative splicing of human NT5E in cirrhosis and hepatocellular carcinoma produces a negative regulator of ecto-5'-nucleotidase (CD73). Mol Biol Cell. 2014; 25:4024-4033.

17. Bowser JL, Blackburn MR, Shipley GL, Molina JG, Dunner K and Broaddus RR. Loss of CD73-mediated actin polymerization promotes endometrial tumor progression. J Clin Invest. 2016; 126:220-238.

18. Sadej R, Inai K, Rajfur Z, Ostapkowicz A, Kohler J, Skladanowski AC, Mitchell BS and Spychala J. Tenascin $\mathrm{C}$ interacts with ecto-5'-nucleotidase $(\mathrm{eN})$ and regulates adenosine generation in cancer cells. Biochim Biophys Acta. 2008; 1782:35-40.

19. Sadej R and Skladanowski AC. Dual, enzymatic and nonenzymatic, function of ecto-5'-nucleotidase (eN, CD73) in migration and invasion of A375 melanoma cells. Acta Biochim Pol. 2012; 59:647-652.

20. Miller DL, Davis JW, Taylor KH, Johnson J, Shi Z, Williams $\mathrm{R}$, Atasoy U, Lewis JS and Stack MS. Identification of a human papillomavirus-associated oncogenic miRNA panel in human oropharyngeal squamous cell carcinoma validated by bioinformatics analysis of the Cancer Genome Atlas. Am J Pathol. 2015; 185:679-692.

21. Bahador R, Taheriazam A, Mirghasemi A, Torkaman A, Shakeri M, Yahaghi E and Goudarzi PK. Tissue expression levels of miR-29b and miR-422a in children, adolescents, and young adults' age groups and their association with prediction of poor prognosis in human osteosarcoma. Tumour Biol. 2015.

22. Zheng G, Du L, Yang X, Zhang X, Wang L, Yang Y, Li $\mathrm{J}$ and Wang C. Serum microRNA panel as biomarkers for early diagnosis of colorectal adenocarcinoma. Br J Cancer. 2014; 111:1985-1992.

23. Omura T, Shimada Y, Nagata T, Okumura T, Fukuoka J, Yamagishi F, Tajika S, Nakajima S, Kawabe A and Tsukada $\mathrm{K}$. Relapse-associated microRNA in gastric cancer patients after S-1 adjuvant chemotherapy. Oncol Rep. 2014; 31:613-618.

24. Qin YZ, Xie XC, Liu HZ, Lai H, Qiu H and Ge LY. Screening and preliminary validation of miRNAs with the regulation of hTERT in colorectal cancer. Oncol Rep. 2015; $33: 2728-2736$.

25. Wang L, Liu M, Zhu H, Rong W, Wu F, An S, Liu F, Feng $\mathrm{L}, \mathrm{Wu} \mathrm{J}$ and $\mathrm{Xu} \mathrm{N}$. Identification of recurrence-related serum microRNAs in hepatocellular carcinoma following hepatectomy. Cancer Biol Ther. 2015; 16:1445-1452.

26. Gougelet A, Pissaloux D, Besse A, Perez J, Duc A, Dutour A, Blay JY and Alberti L. Micro-RNA profiles in osteosarcoma as a predictive tool for ifosfamide response. Int J Cancer. 2011; 129:680-690.

27. Yoshizawa J and Wong D. Salivary microRNAs and oral cancer detection. Methods Mol Biol. 2013; 936:313-324.

28. Jin D, Fan J, Wang L, Thompson LF, Liu A, Daniel BJ, Shin T, Curiel TJ and Zhang B. CD73 on tumor cells impairs antitumor T-cell responses: a novel mechanism of tumor-induced immune suppression. Cancer Res. 2010; 70:2245-2255.

29. Stagg J, Divisekera U, McLaughlin N, Sharkey J, Pommey S, Denoyer D, Dwyer KM and Smyth MJ. Anti-CD73 antibody therapy inhibits breast tumor growth and metastasis. Proc Natl Acad Sci U S A. 2010; 107:1547-1552.

30. Beavis PA, Divisekera U, Paget C, Chow MT, John LB, Devaud C, Dwyer K, Stagg J, Smyth MJ and Darcy PK. Blockade of A2A receptors potently suppresses the metastasis of CD73+ tumors. Proc Natl Acad Sci U S A. 2013; 110:14711-14716.

31. Terp MG, Olesen KA, Arnspang EC, Lund RR, Lagerholm BC, Ditzel HJ and Leth-Larsen R. Anti-human CD73 monoclonal antibody inhibits metastasis formation in human breast cancer by inducing clustering and internalization of CD73 expressed on the surface of cancer cells. J Immunol. 2013; 191:4165-4173.

32. Koszałka P, Gołuńska M, Stanisławowski M, Urban A, Stasiłojć G, Majewski M, Wierzbicki P, Składanowski AC, Bigda J. CD73 on B16F10 melanoma cells in CD73deficient mice promotes tumor growth, angiogenesis, neovascularization, macrophage infiltration and metastasis. Int J Biochem Cell Biol. 2015; 69:1-10.

33. Loi S, Pommey S, Haibe-Kains B, Beavis PA, Darcy PK, Smyth MJ and Stagg J. CD73 promotes anthracycline 
resistance and poor prognosis in triple negative breast cancer. Proc Natl Acad Sci U S A. 2013; 110:11091-11096.

34. Nevedomskaya E, Perryman R, Solanki S, Syed N, Mayboroda OA and Keun HC. A Systems Oncology Approach Identifies NT5E as a Key Metabolic Regulator in Tumor Cells and Modulator of Platinum Sensitivity. J Proteome Res. 2016; 15:280-290.

35. Cappellari AR, Rockenbach L, Dietrich F, Clarimundo V, Glaser T, Braganhol E, Abujamra AL, Roesler R, Ulrich H and Battastini AM. Characterization of ectonucleotidases in human medulloblastoma cell lines: ecto-5'NT/CD73 in metastasis as potential prognostic factor. PLoS One. 2012; 7:e47468.

36. Koszałka P, Pryszlak A, Gołuńska M, Kolasa J, Stasiłojć G, Składanowski AC, Bigda JJ. Inhibition of CD73 stimulates the migration and invasion of B16F10 melanoma cells in vitro, but results in impaired angiogenesis and reduced melanoma growth in vivo. Oncol Rep. 2014; 31:819-827.

37. Virtanen SS, Kukkonen-Macchi A, Vainio M, Elima K, Härkönen PL, Jalkanen S, Yegutkin GG. Adenosine inhibits tumor cell invasion via receptor-independent mechanisms. Mol Cancer Res. 2014; 12:1863-1874.

38. Antonioli L, Blandizzi C, Pacher P, Haskó G. Immunity, inflammation and cancer: a leading role for adenosine. Nat Rev Cancer. 2013; 13:842-857.

39. Wang MX and Ren LM. Growth inhibitory effect and apoptosis induced by extracellular ATP and adenosine on human gastric carcinoma cells: involvement of intracellular uptake of adenosine. Acta Pharmacol Sin. 2006; 27:1085-1092.

40. Leclerc BG, Charlebois R, Chouinard G, Allard B, Pommey S, Saad F and Stagg J. CD73 Expression Is an Independent Prognostic Factor in Prostate Cancer. Clin Cancer Res. 2015.

41. Zhang B, Song B, Wang X, Chang XS, Pang T, Zhang $\mathrm{X}$, Yin $\mathrm{K}$ and Fang GE. The expression and clinical significance of CD73 molecule in human rectal adenocarcinoma. Tumour Biol. 2015; 36:5459-5466.

42. Allard B, Pommey S, Smyth MJ and Stagg J. Targeting CD73 enhances the antitumor activity of anti-PD-1 and anti-CTLA-4 mAbs. Clin Cancer Res. 2013; 19:5626-5635.
43. Allard B, Turcotte M, Spring K, Pommey S, Royal I and Stagg J. Anti-CD73 therapy impairs tumor angiogenesis. Int J Cancer. 2014; 134:1466-1473.

44. Häusler SF, Del Barrio IM, Diessner J, Stein RG, Strohschein J, Hönig A, Dietl J and Wischhusen J. Anti-CD39 and anti-CD73 antibodies A1 and 7G2 improve targeted therapy in ovarian cancer by blocking adenosinedependent immune evasion. Am J Transl Res. 2014; 6:129-139.

45. Stagg J. The double-edge sword effect of anti-CD73 cancer therapy. Oncoimmunology. 2012; 1:217-218.

46. Zhang B. Opportunities and challenges for anti-CD73 cancer therapy. Immunotherapy. 2012; 4:861-865.

47. Wan YW, Allen GI and Liu Z. TCGA2STAT: simple TCGA data access for integrated statistical analysis in R. Bioinformatics. 2015.

48. Amankwatia EB, Chakravarty P, Carey FA, Weidlich $\mathrm{S}$, Steele RJ, Munro AJ, Wolf $\mathrm{CR}$ and Smith G. MicroRNA-224 is associated with colorectal cancer progression and response to 5-fluorouracil-based chemotherapy by KRAS-dependent and -independent mechanisms. Br J Cancer. 2015; 112:1480-1490.

49. Bionda C, Athias A, Poncet D, Alphonse G, Guezguez A, Gambert P, Rodriguez-Lafrasse C and Ardail D. Differential regulation of cell death in head and neck cell carcinoma through alteration of cholesterol levels in lipid rafts microdomains. Biochem Pharmacol. 2008; 75:761-772.

50. Ferrandon S, Magné N, Battiston-Montagne P, Hau-Desbat NH, Diaz O, Beuve M, Constanzo J, Chargari C, Poncet D, Chautard E, Ardail D, Alphonse G and RodriguezLafrasse C. Cellular and molecular portrait of eleven human glioblastoma cell lines under photon and carbon ion irradiation. Cancer Lett. 2015; 360:10-16.

51. Bavaresco L, Bernardi A, Braganhol E, Cappellari AR, Rockenbach L, Farias PF, Wink MR, Delgado-Cañedo A and Battastini AM. The role of ecto-5' -nucleotidase/CD73 in glioma cell line proliferation. Mol Cell Biochem. 2008; 319:61-68. 